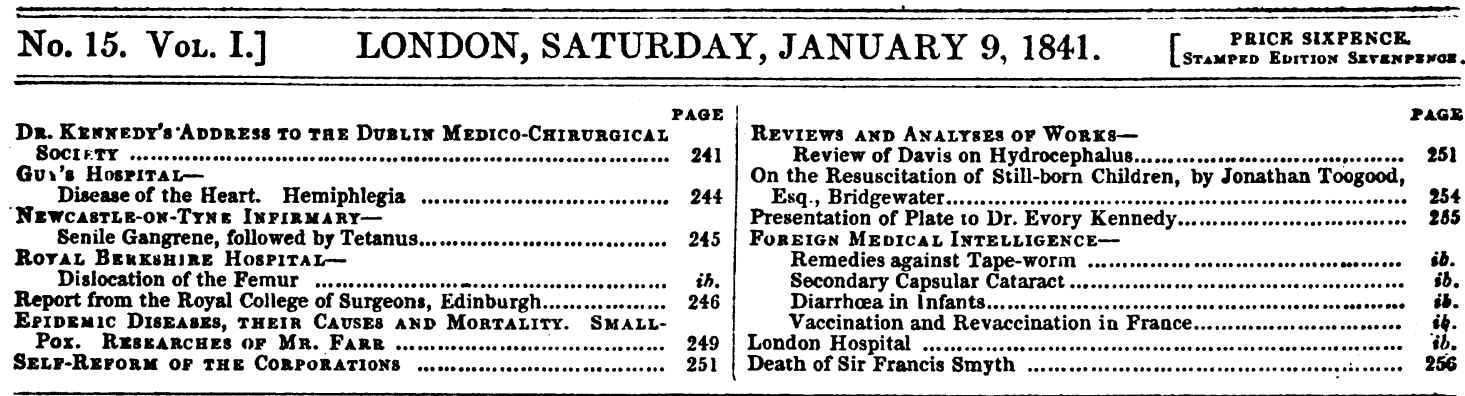

\section{INTRODUCTORY ADDRESS,}

DELIVERED TO THE MEMBERS OP THE MEDICO-CHIRURGICAL SOCIETY OF DUBLIN,

BY DR. EVORY KENNEDY, VICE-PRESIDENT. Sir Printr Cesurtos, Bart., President, in the Chair.*

Mr. President, and Gentl emen,-The prevalent opinion with the public is, that medicine is a science involved in total uncertainty, the practice of which depends upon the chance efforts of the professor, and consequently resting for its successful issue more upon the ingenuity or natural endowments of the physician, than any certain data or principles known or established in the art itself. This opinion, $I$ fear, some medical men have, by their conduct towards each other, and their intercourse with the public, so far sanctioned, as to weaken public confidence in us as a profession, and thus drawn the shafts of ridicule and the sarcasms of the dyspeptic satirist upon us en masse.

We have on record some curious examples of the want of faith in medicine evinced by great men, which, however, appears to have arisen more from the irritation attendant upon disease acting upon the wayward dispositions of men of extraordinary talent, than from a conviction of the inutility of medicine itself. Byron furnishes us with such an example, and himself fell a sacrifice to this irritation and obstinacy. Napoleon affords us a similar example, although from the nature of his malady his reluctance to put himself under treatment had little effect upon its fatal result. His was the most sweeping of all attacks upon medicine, as an art; when, in one of the many disputes he maintained on the subject with those about him, in his last illness, he answered his Italian physician, Antomarchi reasoning thus, "Doctor, no physicing; we are, as I already told you, a machine made to live; we are organized for that purpose, and such is our nature. Do not counteract the living principle; let it alone : leave it the liberty of defending itself; it will do better than your drugs. Our body is a watch, that is intended to go for a given time; the watchmaker cannot open it, and must, on handling, grope his way blindfold and at random; for once that he assists and relieves it, by dint of torturing it with his crooked instruments, he injures it ten times, and at last destroys it." If such sentiments be uttered with regard to us, and by such individuals, we owe it to the science we profess, we owe it to our dignity and respectability, as an enlightened body,

- This addresa was delivered by Dr. Kennedy to a very crowded public meeting of the society. There were present, Sir P. Crampton, and Sir $\mathbf{H}$. Marsh. Barts.; Professors Graves, Harrison, Stokes, Beatty, \&c. with most of the other heads of the profession in Dublin, and many members
of the Irish bar. to command public respect by elevating, as far as in us lies, our profession in the scule of public opinion; but above all, we owe it, as men and Christians, undertaking at the hands of our fellow-creatures a most vital trust, to render ourselves as competent as possible to its performance.

And, gentlemen, although difficulties and uncertainties bestrew our path in the cultivation of this science, which may to our present view appear insuperable, and calculated to deter us from ever reducing it in all its branches to one of demonstration; let us not despair when we recollect that by patient observation, the astronomer has been able to predict the phenomena of the planetary system, and that we have the authority of a Brewster for expécting that meteorological science will, by a multiplication of observations, ere long be reduced to fixed laws,' giving us a power of predetermining those hitherto esteemed most uncertain of all phenomena-atmospherical changes.

If life and death, then, may, in human language, be said to rest with us, or rather on the knowledge we possess, what an awful responsibility does that individual incur who neglects to avail himself of every possible means of extending his knowledge of disease? Picture to yourselves, gentlemen, the idle or self-opinionated physician, who makes light of our efforts here, nor can be persuaded of any benefit to be derived from such societies; see him at the bedside of his patient, possibly the only child of fond parents, or the idolized partner of a devoted wife, on whose exertions an infant family are dependant for support. He stumbles along in his treatment, guided by the dim and scanty light which he possesses, imbibed from the doctrines current in the schools some twenty years ago: the disease proceeds from bad to worse; he pronounces it obstinate, still contirues his routine efforts, and at length when matters become hopeless, perhaps, suggests a consultation; an enlightened member of our profession is called in, but, alas! only to pronounce the patient's doom, and explain to his self-opinionated brother, that a certain plan of treatment adopted earlier in the disease, would have prevented the catastrophe. Of this plan the doctor was totally ignorant, although its merits may have been over and over again discussed by students on this very floor, a fact mentioned, perhaps, at the moment by his consultant. Observe this individual return to the bed of death to announce to the distracted and bereaved family the completion of his work. What must be his self-degradation! What his agony of regrets! Nay, so acute are these, that even the dread of suffering in professional character, is lost sight of in his stronger feelings of the moment.

But, alas! remorse is unavailing; the grave has closed over the victim of his ignorance, and the cup of bereavement and misery has been dealt out hy his hand to the 
helpless family of the man who reposed implicit confidence in him.

As this may be especially esteemed the era of utilitarianism, let us in the first instance inquire 'the cui bono' of such an institution as the Medico-Chimurgical Society. This may be pronounced to be the improvement of the student and practitioner in medicine in all its walks, and the extension of the bounds of our science.

This society is from its constitution peculiarly adapted to carry out these joint objects. Whilst its managenent and the preparation of papers rest, in a great measure, with the student and junıor practitioner, for whose improvement it was more especially established, it solicits all practitioners to take an active part in its proceediugs, and has, at least in its earlier periods, frequently enjoyed the advantages to be derived from the presence of the most enlightened heads of the profession. 'Thus motives of praiseworthy emulation call out the exertions of the medical student from the commencement of his professional career, affording higher and nobler objects to bound his field of enterprize, than the mere attaininent of his qualification to practise. He sees the science he is studying through an unlimited philosophic mentium, nor rests satisfied with having his professional information narrowed within the sphere of the grinder's telescope. The existence of such a society as this convinces him that there are other and more moving inducements to exertion.

If the energies of the members be well directed by your well-selected committee, assisted by the counsel and advice of those distinguished individuals whom you have elected to honorary appointments in the society, the mind of the student will be opened, and his attention directed to a more enlarged and important study of medicine generally, in place of having his intellect cramped, and his views narrowed by devoting himself to the acquisition of mere scholastic information, much of which he must unlearn on coming to practice. We must, in urging the medical student to exertion, use every fair means of calling out his energies, as our profession, unlike its learned sisters-law and divinity, has not those tempting trappings, croziers and mitres, lawn sleeves and ermine; neither those comfortable resting-places, the bench, the throne, the woolsack; nor those titles of ennoblement so euphonious to the man of ambition, to tempt us to extraordinary eflort.

Do not misunderstand me, gentlemen; sweet as all these may appear to the man of the world, it is not to regret their want that I draw your attention to them. If our profession be such as to render it idle our expecting extraordinary honours or wealth to flow in upon us, or, as that keen satirist, Juvenal, has it-

\section{"Divitiæ ut crescant, ut opes: ut maxima toto}

let us at least recollect with him, "Nulla aconita bibuntur fictilibus," and, like true philosophers, respond with his conclusion-" Tunc illa time, cum pocula sumes gemmata,

We have, however, motives just as cogent, although not $s 0$ bruited, to urge us to exertion. Is it not sufficient to arouse our energies, to be aware that with us it rests to assuage pain and suffering, and stand between death and his prey? Is it no reward for our exertions, to be conscious that in some of the most fatal maladies, when the bolt has been shot by him "under whose foot the Creator hath put all things," it is our privilege, enlightened by that science to the improvement of which this society conduces, to place our shield over the victim, and turn aside the shaft to spend itself on the idle wind.

Although honours are not showered upon us as a profession, yet it has not been wanting in dignity or importance. Its professors amongst the ancients were deified, and history records that the continuance of peace or war even hung upon the possession of an eminent physician. Witness the case of Tribunus, whom Procopius, in his Bella Persica, informs us was so eminently esteemed, that
Chosroes, in treating for peace with Justinian, would not so much as make a truce without one condition, namely, that Tribunus, whose skill in physic he wanted, should be sent to him; and the historian remarks that when this was done, a truce was concluded for five years.

Crowned heads made the subject of medicine their study in earlier ages, and we have it on record that their heirs were even sent into strange kingdoms, in which the fame of their schools was great, to perfect themselves in this art. This was the case with Josina, the ninth king of Scutland, who was educated by the physicians in Ireland. In the dark ages, again, its profession was as:umed by the ministers of God, as an occupation pleasing to their Divine Master, and quite compatible with their high calling. But what further proof need be required of the dignity of our pursuit than the fact, that healing the sick was the occupation most pleasing to and most practised by the Divine Pliysician when on earth amongst us?*

To guard my younger friends against falling into such errors, I cannot aroid alluding to the charucter of Uranius, a plysician who practised in Constantinople about the sixth century, as recorded by Agathias. He washy birtha Syrian, by profession a physician, who, having not the least knowledge of Aristotle or the ancient philosophy, had nevertheless a high cunceit of his own learning, which ouly consisted in fluency of expression, and a peremptoriness in maintaining whatever parıdox he advanced. He was generally found either in the public piazzas adjoining the court, or at the booksellers' shups, and there disputed with several persons who had as little tincture of learning as of morality, and that about questions of a high nature, which he argued with great rashness and presumption. The historian goes on thus (and mark me. gentlemen, I draw no parallel with the society here alluded to and the learned body I have now the honour to address):- "The club," he says, "met generally in the evening, after the debauch of the day, and in a libertine manner discoursed of the most sublime and most difficult questions, without either convincing others or being themselves convinced: so that they parted in the opinion which they severally were prepossessed with, and usually ended their quarrels, like gamesters, with bitter reproaches and hot words." See here the result of their disputes, which commonly concluded in a mutual aversion to each other; amongst thein Uranius, our friend, was one of the first rank, and made as great a bustle as Thersites does in Homer. But he had no abilities, for want of solid learning, to lay down any of his arguments in due form : which made lim eager to answer doubts before they were raised, and sometimes, instead of answering objections, to ask the reason of their being raised. In shoit, he constantly inverted the rules which are ordinarily observed in regular conferences, which must always hinder the discovery of truth. He affected scepticism in every thing, and formed his answers upon the model of Pyrrho and Sextus Empiricus. He imagined that the opinion he was of, "that there could be no knowledge of any thing," would make him perfectly easy, and free him entirely from any remorse or trouble of mind. His capacity being thus very mean, he could only impose upon the simple and the credulous; and if he was at a loss in any science, he was much more so in the knowledge of the world, and the conversation of the more polite part of it.

Gentlemen, it has not, as far as I am acquainted with this society, as yet been our evil fortune to have a second Uranius amongst us; and long may we continue so! But if such a one should start up-as, frum what I know of your constitution, I feel convinced he could not urge the apology of Socrates in Gorgias, "that if he knew little, those he disputed with knew less"-I merely leave him to your tender mercies, with the request that you may not spare him on my account, or through any feeling of delicacy towards me, as having thus unbidden introduced him to your notice.

- We have here omitted a considerable portion of Dr. Kennedz's address, which has already appeared in print. 
I repeat it, gentlemen, one of the great objects of this society will prove the causing practitioner to analyse the merits of our views in daily acceptation. Much as one must ascribe to experience and observation, which I think Swift has somewhere designated "as an old man's memory," we should recollect that these do not always go together, as it is quite possible for a man to have seen a great deal of disedse, without having observed or reasoned upon it. Such persons fall into a routine practice, and even maintain a certain character, writing long prescriptions, and looking as wise as judges, and yet get crowned with grey hairs, w nderfully innocent of their profession as a science. Permit me to apply to these gentlemen Pope's happy lines, slightly altered to suit our object :-

\section{Ah,-think not, masters, more true dulness lies In folly's cap, than wisdopin's grave disguise. Like bu'ys that never sink into the flood, These miscalled docto's do but lie and nod Theirs 'tis to take plump fees in every house, And use pomposity for lack of nous.}

I could tell a few anecdotes of such characters; but as these ure (however anuusing) distres.ing, when we consider the awful responsibilities of the medical practitioner, we shall abstain. This class of persons is not confined to our profession, however; I stand indebted to my friend, $\mathrm{Mr}$. Napier, the talented and eminent barrister and professor of coinmon law to the Dublin Law Institute, for a specimen of the same genus in the legal profession. A gentleman, a routine practitioner, made it a boast that he arrived at high public confidence without his having ever read a law book; he, however, kept a rule book, carefully indexed This book falling into the hands of an intelligent friend, he was struck with the momentous words, "Great mind," standing out prominently in the index. You may form some idea of this gentleman's eagerness and anxiety in referring to the text for an elucidation of these engrossing words, and the overwhelming light he expected to burst upon him by the perusal of the passage so characterized. Judge, then, of how his expectations were realized by discovering the following :-

"Lord Mansfield had a great mind to nonsuit the plaintiff."

I should, however, mention that this occurred at the English bar.

Now, gentlemen, although such a specimen as this might occur in any profession, or in any country-

\section{" Jove being alike to Latian and to Phrygian,}

For you well know that wit's of no religion,"

yet.I should only earn the cap and bells were I hardy enough to attack the bar; and, as Pope has it,

\section{"With you, my critiss, in the chequered shade,}

Admire new lights through holes ourselves had made."

On the contrary, as a British subject, and one who has possessed the privilege of friendship and association with many of its members, I feel a true pride in saying, that a more enlightened, higher principled, or an abler class of men, do not exist in any country than the bar of Great Britain.

It is further gratifying to find, in this age of enlightenment, that this learned body, actuated by a most praiseworthy desire to establish a scientific and practical system of education for the student of law in Ireland, have arrived at the conclusion that (iabbet's Digest is not incompatible with proper attention to the young gentlemen's digestive organs; and that Blackstone's Commentaries and Coke upon Littleton will not prove too much for their stomachs, when euperadded to their roast mutton and rough port. In fact, to sink metaphor, even at the eleventh hour, the heads of the legal profession have adopted a similar system of professional education to that long in operation in ours.

It is far from my intention, gentlemen, to convey to you the impression that our profession, as a body in this country, have neglected to labour for the insprovement of our science, or that their labour has not brought forth an abundant harvest. As in the darker ages, the doctors of Ireland (from the periud of the foundation of the MurOllamham or university of Tara, in the year of the world 3240 , to that of $O^{\prime} C l a c h a n, " N o s t r a$ Clacan celeberrimus arte," in the 17 th century) stood out as a beacon to guide the followers of science through the murky mass of darkness in which the divinity they sought was elsewhere enveloped; so in these more enlightened times, when she is standing exposed to our admiring gaze, on the approach of the inidday splendour of successfiul investigation, I am proud to say that the school of this city holds a high eminence in the assistance it affords to effect this des rable object.

I was at some pains on the occusion of delivering an introductory address, sume iwo years since, to the Dublin Obstetrical Society, to satisfy myself, as tar as leisure could be devoted to this investigation from more pressing professional avocations, of the state of our science in Ireland in the earlier periods of its history; and although I barely entered on the threshold of a wide and rich field of investigation, as that lecture, which afterwards found its way into print, can testify, yet I saw enough of the subject to quite satisfy me that a more open or tempting pursuit does not exist for the young I rish physician, tinctured with research and patriotism, provided he have spare time on his hands, and understand that too much neglected study, his native language. I need scarcely call to the mind of my present hearers that our enlightened president has attested the importance of this inquiry by his interesting researches on the early state of surgery in this co intry, given to the public in his late address to the College of Surgeons; and that my friend, Dr. Aquilla Smith, has also lent his aid towards its elucidation. I wish from my heart 1 could spirit up some one of my present listeners, thus endowed, to take up this subject $a b$ ovo. Our libraries are overflowing with material for this investigation, which was lately on the eve of being much simplified, if not partially carried out by the wise determination of the government of this country attaching that all-import:Int addition, the memoir, to the great national undertaking, the ordnance survey of Ireland. Every true patriot was cheered with the anticipation of the vast results to be derived from this magnificent undertaking, guided by such minds as a Colby and a Larcom, and carried out by Portlock, Petrie, and Donovan; but alas! from what cause I am at a loss to divine, surely not mistaken parsimony (tor its results, as regards the entichment of the country, were incalculable), the cup of hope and expectation has beenda shed from our lips, just as, parched and tantalized, we had tasted of its sweetness in the publication of their first admirable report on Templemore.

As 1 have hitherto referred more to the general objects of such societies, we shall now briefly allude to those somewhat peculiar to this. As its name implies, it takes in the whole range of medical and surgical science. It was established especially for the improvement of the students themselves, and by their own efforts. That their communications have not been the crude productions of mere tyros, is proved by the fact, that several of them have been selected by the periodical press for publication, both here and in London. I may also add that most of the founders are now in the enjoyment of appointments of public trust, or engaged in communicating that information (to the acquisition of which they so zealouily devoted themselves) to the rising class of students in this city. A justifiable emulation has been excited by the dispensation of honorary distinctions to such members as have read papers, or been most forward in advancing its interests. Thus calling out the energies of the members in the manner most grateful to the society at large, without exciting envy or jealousy among them. This secures the effort, whilst it establishes a kindly and unassuming interzourse; for, as St. Austin beautifully remarks, "Ubi charitas, ibi humilitas, ubi humilitas, ibi pax." It has been suggested to me to call the attention of those individuals who intend favouring the society with communications, that as it is their wish to read s 2 
and discuss three papers on each night of meeting, it were well to frame them of such a length as will admit of this. As this is a delicate subject for one to broach who is in momentary dread " ne me Crispini scrinia lippi compilasse putes," I shall, therefore, only so far allude to it as to bring to the recollection of my hearers the admirable advice of Horace upon this subject; taking the unpardonable liberty with this author and my audience of giving it as rendered by Francis, as it appears to me rather to have gained in point by the translation :-

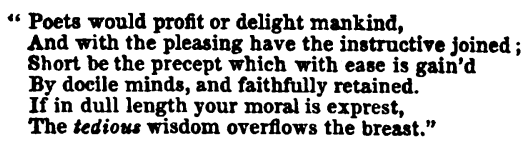

\section{HOSPITAL REPORTS.}

HEMTPHLEGA-DISEASE OF THE CARDIAC VALVES.-DEATH.

JoHn LYNCH, æt. 24, of sallow complexion and emaciated frame, was admitted into Guy's Hospital, March 22d, 1840, complaining of paralysis of the right side. He states that five months since he was suddenly seized with giddiness; that he then fell into a fit, and remained insensible for a fortnight; and that upon recovery from this state he found himself deprived of the use of the entire right side of his body. He has since been twice attacked with similar fits, but each of these lasted only about an hour. They were both attended with loss of voluntary power and sensation, and foaming at the mouth; but there was no struggling, neither did he, as far as he remembers, bite his tongue.

On admission, his articulation was imperfect, and the power of motion in the right upper and lower extremities very slight, if any; sensation, however, being perfect. There is a vacancy of expression in the countenance; the eyes are dull, and he suffers occasionally from vertigo. The heart's inpulse is very powerfully felt between the fourth and fifth ribs, and the second stroke is accompanied with a distinct bruit of a seesaw sound. On placing the hand over the region of the heart, a purring treinulous sensation is communicated to it. The pupils are naturally affected by light. Pulse 90 ; tongue coated; bowe!s regular; much thirst, but little desire for food. He seems to have lived temperately, and generally to have enjoyed good health previous to the first attack. The last fit occurred ten days since. To be cupped on the neck to eight ounces; blue pill, three grains, thrice a day; saline mixture, thrice a day.

On the 27th his mouth was becoming affected, and on the following day he was ordered to take only one pill daily.

April 1. Has not suffered from vertigo for several days. Pulse 100, compressible. The other symptoms remain much the same.

8. Speech improving, and he appears to be gradually regaining the use of the affected limbs. Pulse 105; tongue clean; no thirst; appetite good. He has not had any return of the vertigo.

10. He has had a fit this morning in his sleep; not ushered in by headaches, or any premonitory symptom. The patient in the next bed says that he saw him lying for five minutes apparently almost choked, and that he afterwards breathed heavily and foamed at the mouth. The fit lasted about twenty minutes, and he then fell asleep for seven hours. On waking he appeared to wander in his mind. The following morning he was ordered iodine, one grain; iodine of potass, twenty-four grains; tincture of lavender, four drachms; distilled water, six ounces.

15. There are occasionally involuntary twitchings about the arms and legs. He appears to be rather stronger in the affected side. There is no headache or giddiness. Heart's action still very powerful; the bruit heard at any
part of the chest.

20. He is stronger to-day than he has been for several days past. There is a constant pain in the right elbow, which he describes as similar to what he has felt in the shoulder when gaining strength in the arm. He has had a slight headache for half an hour after waking in the morning the last three days; and on lookirg downwards, or to either side, has had double vision. Heart's action not so violent; pulse 92 ; appetite good.

22: Has had another fit during the night. A few minutes after talking with the patient in the next bed, he was suddenly seized with trembling and insensibility, in which state he remained for half an hour; he then became violently convulsed - biting his tongue severely - for about ten minutes, and finally sank into a state (apparently) of coma. There were no immediate premonitory symptoms. He complains now (2 P.M.) of a slight headache. The cheeks are a little flushed. The pain in the elbow is gone off; heart's impulse less violent; pulse 92, soft; tongue clean; bowels open. He thinks the affected limbs are stronger. Ordered a seton in the neck.

29. Heart's impulse very great to day-sawing sound very distinct. Pulse 120, strong; no headache; tongue furred; bowels open.

May 3. There is double vision in left eye. When desirous of seeing clearly any distant object, he is obliged to close it and use the right eye only. Pupils obedient to light. No headache. Pulse 108, small, and compressible.

6. An abscess was opened to-day at the side of the neck. Pulse 100, jerking. He makes but little progress in regaining the use of the affected limbs. Has no headache. Other symptoms as before.

16. Got up to-day. Feels generally stronger. There is still the same vacant expression of countenance he has had all along. The heart's impulse is much less violent. Still has double vision on looking in certain directions. Pulse 108; tongue clean; appetite good.

21. Complains of pain in the forehead, not, he says, like that of common headache. Continues to see better when using the right eye only. Pupils contract and dilate naturally. No muscæ volitantes. Pulse 100, soft; bowels open twice daily. Ordered twelve leeches to the temples. 24. Weight of head and drowsiness relieved. Vision remains in the same state. Other symptoms as before. Three grains of sulphate of zinc, thrice a day.

June 1. His vision is much improved. There is no pain or weight about the head. The heart's impulse is by no means so violent as it was a fortnight since; and the thrilling sensation which was given to the hand is now quite absent. The bruit still exists. Pulse 92, not very compressible; tongue clean; appetite good. Continue remedies.

He continued much in the same state until the afternoon of the 20th, when he experienced considerable drowsiness and sense of weight about the head, with general indisposition. He therefore went to bed; and on the rurse going to see him at 12 P.M. she found him dead.

\section{Post-mortem Appearunces.}

On opening the chest, the upper lobe of the left lung was found to be adherent to the costal pleura; the right lung, however, being quite free. The structure of both was of a dark colour, being congested with blood, and odematous. The left ventricle of the heart, which was altogether enlarged, was dilated, and slightly hypertrophied. Only a small portion of the anterior attachment of the mitral valve remained, the rest having been destroyed by ulceration; but the posterior one was quite healthy. The lining membrane of the right auricle was thickened, and covered by a layer of firm lymph. The free margins of the sigmoid valves were considerably thickened, and partly destroyed by ulceration.

The membranes of the brain were found to be free from disease; but immediately below the surface of the left. hemisphere, in its posterior lobe, was found a cavity of the size of a pigeon's egg, and containing an old clot of extravasated blood, very firm, especially in its centre. The cortical and medullary structures immediately surrounding 